\title{
Comparative randomized study on the efficaciousness of endoscopic bipolar prostate resection versus monopolar resection technique. 3 year follow-up
}

\author{
Roberto Giulianelli, Luca Albanesi, Francesco Attisani, Barbara Cristina Gentile, \\ Giorgio Vincenti, Francesco Pisanti, Teuta Shestani, Luca Mavilla, David Granata, \\ Manlio Schettini \\ Division of Urology - Nuova Villa Claudia Clinic, Rome, Italy.
}

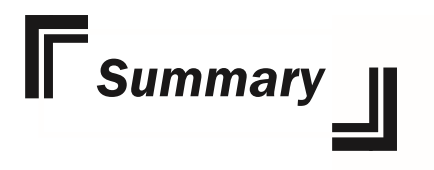

Objective: Transurethral resection of the prostate (TURP) is the current optimal therapy for the relief of bladder outflow obstruction, with subjective and objective success rate of 85 to $90 \%$. Aim of this study was to evaluate efficacy and safety of Plasmakinetic energy (Gyrus electro surgical system), which produces vaporization of tissue immersed in isotonic saline against standard monopolar transurethral resection of the prostate.

Methods: From January 2002 to April 2002, 160 consecutive patients, who had low urinary tract symptoms (LUTS) of benign prostatic hyperplasia (BPH) were enrolled in this study. Patients were randomised to undergo bipolar TURP ( 80 patients) or monopolar TURP (80 patients). Preoperative work-up was assessed by administering IPSS, IIEF-5 and Qol questionnaires. All patients were submitted to uroflowmetry, transrectal ultrasound (TRUS), post-voidal residual urine measurement and PSA determination. In the two groups, IPSS, IIEF-5 and Qol, uroflowmetry, TRUS, post-voidal residual urine measurement, PSA determination and number of reoperations were evaluated at 1, 3, 6, 12, 18, 24, 30 and 36 months follow up, and then every year. Furthermore, in both groups operative time, resected tissue weight and perioperative complications were analysed. Total postoperative catheter time, total post-operative hospital stay, haemoglobin loss were also recorded in the two groups.

Results: Comparative data on IPSS symptom score, IIEF-5, Qol, PSA, peak urinary flow rate and post-void residual urine volume were similar in the two groups but showed a significant improvement respect to baseline values. The postoperative haemoglobin levels, postoperative catheterization time, hospital stay and 3-year overall surgical re-treatment-free rate were significantly better in the bipolar group.

Conclusions: Bipolar TURP has a comparable outcome to standard monopolar TURP at short and medium term regard to subjective and objective outcome measurements. Its impact on bladder outlet function is also similar to that of monopolar TURP. Improvement in IPSS, Qol index, IIEF-5, $Q_{\max }$ and post-void residual urine volume were comparable in both group denoting similar efficacy of the techniques.

KEY WORDS: Bipolar TURP; Monopolar TURP; Outcome; Gyrus device.

\section{INTRODUCTION}

Benign Prostatic Hyperplasia (BPH) is a highly prevalent medical condition worldwide. The prevalence of Lower Urinary Tract Symptoms (LUTS) associated with BPH among older and middle-aged men is significant and is growing alongside the increasing age of Western populations. It has been calculated that approximately $30 \%$ of the male population in Europe and the United States have a chance of undergoing to standard transurethral 
resection of the prostate (TURP) during their lifetimes (1). Transurethral resection of the prostate (TURP) is the current optimal therapy for the relief of bladder outflow obstruction, with subjective and objective success rate of 85 to $90 \%$ (2). Besides these excellent success rate, bleeding, transurethral resection syndrome, urinary tract infection, retrograde ejaculation and incontinence are the complications associated with the procedure (3). These complications have been estimated to develop in approximately $15 \%$ of the patients (4) and they may sometimes be of clinical relevance (5). Contemporary TURP uses a monopolar electrocautery system in which the current passes through the patient's body: from the active electrode, placed on the resectoscope, towards the return plate, normally placed on the patient's leg. This has several disadvantages such as heating of deeper tissue, nervous or muscle stimulation and possible malfunction of cardiac pace-maker (6).

Resectoscopes using bipolar electrocautery offer an alternative with active and return electrode placed on the same axis on the resectoscope using high current locally but with limited negative effects at distance. Another risk of standard monopolar TURP is the absorption of hypoosmolar irrigation fluid causing the TUR syndrome. As bipolar resectoscopes use isotonic saline solution for irrigation, the risk of TUR syndrome is eliminated.

The first bipolar device for endourological procedures was the Gyrus device using the bipolar electrocautery to electrovaporize the prostate (7).

Aim of this study was to evaluate efficacy and safety of Plasmakinetic energy (Gyrus electro surgical system), which produces vaporisation of tissue immersed in isotonic saline versus standard monopolar transurethral resection of the prostate.

\section{MATERIALS AND METHOdS}

From January 2002 to April 2002, 160 consecutive patients, with a mean age of $63.34 \pm 7.1$ years, who had LUTS of BPH were enrolled in this study. Out of them, 80 patients with a mean age of $62.5 \pm 6.9$ years were randomised to undergo bipolar TURP (Gyrus group) and 80 with a mean age of $64.18 \pm 7.2$ years to monopolar TURP (Traditional group). All surgical procedures were performed by the same surgeon who was fully trained in bipolar and monopolar TURP.

Preoperative work-up included administration of IPSS, IIEF-5 and Qol questionnaires. All patients were submitted to uroflowmetry, transurethral ultrasound (TRUS), post-voidal residual urine measurement and PSA determination.

The patients provides informed written consent and were randomized to the traditional or Gyrus group with a schedule balanced in blocks of 4 . All patients were operated on within 4 weeks of randomization. Exclusion criteria were patients with documented or suspected prostate cancer, bladder calculus, neurogenic bladder, previous prostate surgery, renal impairment, associated hydronephrosis and urethral stricture.

The instruments ( $12^{\circ}$ Storz $24.5 \mathrm{~F}$ resectoscope) and the operative technique were the same of monopolar and bipolar TURP. In the traditional group the monopolar
TURP was performed by a Gyrus ACMI generator, with a standard tungsten wire loop using a cutting current of 80 $\mathrm{W}$ and coagulating current of $160 \mathrm{~W}$. In this group standard TURP was carried-out using irrigation with a mannitol-sorbitol solution. In the bipolar group, TURP was carried out using a Gyrus Plasmakinetic generator and saline irrigation that allowed electric current to complete the circuit without passing through the patient. The Gyrus Plasmakinetic system is a bipolar coaxial system with the active and return electrodes located in the same axis, separated by a ceramic insulator. We performed bipolar TURP with a cutting current of $120 \mathrm{~W}$ and coagulating current of $80 \mathrm{~W}$.

At the end of the operation a 20 Fr. Dufour catheter was inserted and the bladder was continuously irrigated depending on the amount of postoperative bleeding. All tissue retrieved from each patient was investigated histologically. All patients were operated in peridural anesthesia.

Perioperative and postoperative outcomes were evaluated. In both groups operative time, resected tissue weight and perioperative complications were analysed. Total postoperative catheter time, total post-operative hospital stay, haemoglobin loss were also recorded in the two groups.

In both groups, IPSS, IIEF-5 and Qol scores, uroflowmetry and TRUS measurements of post-voidal residual urine, PSA determinations and number of reoperations were evaluated at $1,3,6,12,18,24,30$ and 36 months. The results were analysed with the use of descriptive statistic and with paired $t$ test and chi-square test to compare the continuous variables and categorical data. Significant differences were considered at $p<0.05$. Baseline characteristics, perioperative data and postoperative interim analyses of IPSS symptom scores, peak urinary flow rates and residual volumes in the two groups were compared using the 2-sided Mann-Whitney test. Perioperative and postoperative adverse events were compared with the 2tailed chi-square test (exact Fisher's test).

\section{RESULTS}

Of 160 men 80 each were randomised to monopolar and bipolar TURP. The patient population and their preoperative characteristics are shown in Table 1. There was no statistically significant difference in any parameter between the two groups. The perioperative data are shown in Table 2 and the postoperative data are shown in Table 3. The resection time and the weight of resected prostate tissue were not significantly different in the two groups. Histological examination of the retrieved tissue revealed BPH and varying degrees of prostatitis. Incidental carcinoma of the prostate was found in 7 (4.37\%) patients ( 6 pTla and 1 pTlb): 5 in the monopolar group and 2 in the bipolar group respectively.

Table 3 shows comparative data of IPSS, IIEF- 5 and Qol, PSA, peak urinary flow rates and post-void residual urine volumes in the two groups at 1, 3, 6, 12, 24, 30 and 36 months.

Compared to baseline there was an highly significant improvement for each parameter at all intervals in each group ( $\mathrm{p}<0.0001)$. On the contrary there was no signif- 
Table 1.

\begin{tabular}{|lll|}
\hline Preoperative data & Bipolar TURP & Monopolar TURP \\
\hline Age $($ years $)$ & $62.5 \pm 6.9$ & $64.18 \pm 7.2$ \\
\hline PSA $(\mathrm{ng} / \mathrm{ml})$ & $2.2 \pm 0.5$ & $2.8 \pm 1.0$ \\
\hline Prostate volume $(\mathrm{ml})$ & $47.8 \pm 14.6$ & $50 \pm 9.8$ \\
\hline IPSS & $22.3 \pm 3.2$ & $23.4 \pm 1.8$ \\
\hline Qol & $3.3 \pm 2.1$ & $3.0 \pm 2.5$ \\
\hline$Q_{\max }(\mathrm{ml} / \mathrm{sec})$ & $8.9 \pm 2.9$ & $6.5 \pm 4.8$ \\
\hline PVR & $243 \pm 241.6$ & $187 \pm 195$ \\
\hline $\mathrm{IIEF}-5$ & $16 \pm 3.6$ & $17 \pm 2.5$ \\
\hline $\mathrm{Hb}$ & $14.88 \pm 0.71$ & $14.52 \pm 0.71$ \\
\hline
\end{tabular}

Table 2.

\begin{tabular}{|lll|}
\hline Perioperative data & Bipolar TURP & Monopolar TURP \\
\hline Resection time $(\mathrm{min})$ & $58 \pm 14.6$ & $59 \pm 18$ \\
\hline Resected prostate tissue $(\mathrm{gr})$ & $30.6 \pm 8.6$ & $29.5 \pm 7.8$ \\
\hline $\mathrm{Hb}(\mathrm{gr} / \mathrm{dl})$ & $13.6 \pm 0.6$ & $10.4 \pm 1.2$ \\
\hline Time to catheterization $(\mathrm{h})$ & $24 \pm 12$ & $48 \pm 48$ \\
\hline Hospital stay $(\mathrm{h})$ & $48 \pm 6$ & $72 \pm 48$ \\
\hline
\end{tabular}

PVR decreased to $97 \mathrm{ml}$. (SD $\pm 57.6, \mathrm{p}<0.05)$. At 3,6 and 12 months, mean PVR was $81 \mathrm{ml}(\mathrm{SD} \pm 17.6, \mathrm{p}<$ $0,05), 22.5(\mathrm{SD} \pm 15.6, \mathrm{p}<0,001)$ and $10 \mathrm{ml}(\mathrm{SD} \pm 10$, $\mathrm{p}<0.001$ ), respectively.

The IPSS in the Bipolar group fell from $22.3(\mathrm{SD} \pm 3.2)$ to $12.8(\mathrm{SD} \pm 1.2)$ at 1 month, $5.3(\mathrm{SD} \pm 1.4)$ at 3 months and $5.0(\mathrm{SD} \pm 1.2)$ at 6 months respectively. There was also a significant modification of the Qol score (baseline 3.3), which was $2.3(\mathrm{p}<0.01)$ at 1 month, 1.1 $(\mathrm{p}<0.001)$ at 6 months, and 0.9 ( $\mathrm{p}<0.001)$ at 12 months (Figure 2). Those results were stable in the following months.

The mean preoperative haemoglobin fell from 14.88 $\mathrm{mg} / \mathrm{dl}(\mathrm{SD} \pm 0.71)$ and $14.52 \mathrm{mg} / \mathrm{dl}(\mathrm{SD} \pm 0.71)$ in the monopolar and bipolar group to postoperative values of $10.4(\mathrm{SD} \pm 1.2)$ and $13.6(\mathrm{SD} \pm 0.6)$ respectively.

The postoperative haemoglobin levels were lower in monopolar than bipolar group, and in the monopolar group 3 patients required transfusions. Postoperative bladder irrigation was always stopped on the first postoperative day.

Median postoperative catheterization time and hospital stay time were 1 and 2 days in the bipolar group an 2 and 3 days in the monopolar group. Nine patients in monopolar group and none in bipolar group were unable to void after initial removal of the catheter; they need to have the catheter reinserted and were discharged 2 days later. Four patients in monopolar group and one

Table 3.

\begin{tabular}{|c|c|c|c|c|c|c|c|c|c|c|c|c|c|c|c|c|}
\hline \multirow{2}{*}{$\begin{array}{l}\text { Postoperative data } \\
\text { Follow-up (months) }\end{array}$} & \multicolumn{8}{|c|}{ Bipolar TURP } & \multicolumn{8}{|c|}{ Monopolar TURP } \\
\hline & 1 & 3 & 6 & 12 & 18 & 24 & 30 & 36 & 1 & 3 & 6 & 12 & 18 & 24 & 30 & 36 \\
\hline IPSS & 12.8 & 5.3 & 5.0 & 4.5 & 4.2 & 3.0 & 3.0 & 2.0 & 8.8 & 7.8 & 7.0 & 5.3 & 5.0 & 4.8 & 4.8 & 4.0 \\
\hline Qol & 2.3 & 1.7 & 1.1 & 0.9 & 0.6 & 0.5 & 0.5 & 0.5 & 1.8 & 1.7 & 1.7 & 1.5 & 1.3 & 1.0 & 1.0 & 1.0 \\
\hline $\mathrm{Q}_{\max }$ & 19.7 & 24.3 & 25.2 & 26.7 & 25.2 & 23.2 & 22.8 & 23.0 & 21.0 & 23.7 & 23.0 & 23.5 & 24.0 & 23.4 & 20.0 & 20.0 \\
\hline PVR & 97 & 81 & 22.5 & 10 & 10 & 0 & 0 & 0 & 75 & 45 & 15 & 10 & 10 & 0 & 0 & 0 \\
\hline PSA & 0.55 & 0.90 & 0.95 & 0.90 & & 0.9 & & 0.9 & 0.60 & 0.90 & 1.00 & 1.00 & & 1.15 & & 1.50 \\
\hline IIEF-5 & 21 & 23 & 23 & 24 & 24 & 24 & 24 & 24 & 20 & 21 & 22 & 22 & 24 & 24 & 24 & 24 \\
\hline
\end{tabular}

icant difference between the 2 groups for peak flow rate, improvement in IPPS, IIEF-5 and Qol score, PSA modification and post-void residual urine volume at all postoperative follow-up evaluations. Correlations between baseline and change from baseline showed that in each group improvement was more pronounced in patients with more severe preoperative symptoms and micturition impairment. In the bipolar group the $\mathrm{Q}_{\max }$ increased from $8.9 \mathrm{ml} / \mathrm{sec}(\mathrm{SD} \pm 2.9)$ preoperatively to $19.7 \mathrm{ml} / \mathrm{sec}$ $(\mathrm{SD} \pm 5)$ after 1 month $(\mathrm{p}<0.01)$. At 3, 6 and 12 months, $\mathrm{Q}_{\max }$ increased to $24.3 \mathrm{ml} / \mathrm{sec}(\mathrm{SD} \pm 3.2, \mathrm{p}<0.01), 25.2$ $\mathrm{ml} / \mathrm{sec}(\mathrm{SD} \pm 1.2, \mathrm{p}<0.001)$ and $26.7(\mathrm{SD} \pm 2.2$, $\mathrm{p}<0.001$ ), respectively (Figure 1 ). In the same group, post-void residual urine volume (PVR) fell down substantially from the preoperative levels. The baseline value was 243 (SD \pm 241.6$)$; after removal of the catheter, the mean in bipolar group developed clot retention within 3 weeks from surgery and in the monopolar group other two patients developed haematuria within 1 week from TURP, all required readmission for cystoscopy and continuous bladder irrigation.

In the monopolar group there were two cases of clinically evident TUR syndrome and none in bipolar group. Two patients in the monopolar group and fifteen in the bipolar group had postoperative irritative symptoms, which required occasional anticholinergic therapy. Urinary tract infections developed in two patients in monopolar group and were treated with appropriate antibiotics.

One year after TURP 154 patients (75 in the monopolar and 79 in the bipolar group) were assessed for urinary continence and number of retreaments. None patient 
Figure 1.

3 year $Q_{\max }$ improvement in monopolar and bipolar group. Compared to baseline there was an highly significant improvement at all intervals in each group ( $p<0.0001)$.

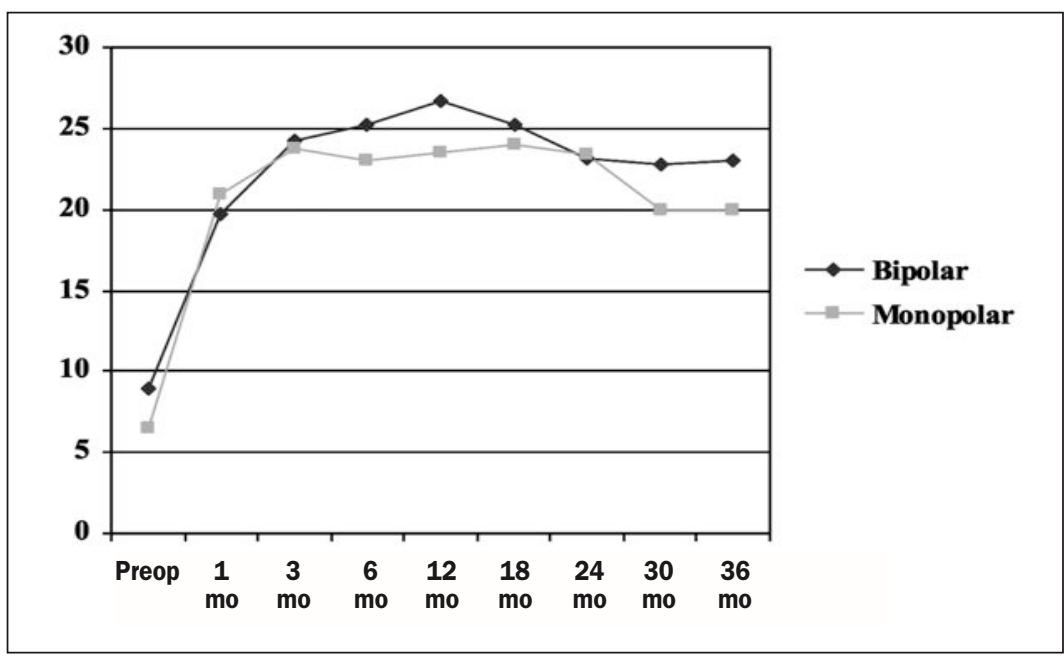

Figure 2.

Kaplan-Meier curves, 3 year overall surgical re-treatment-free rate.

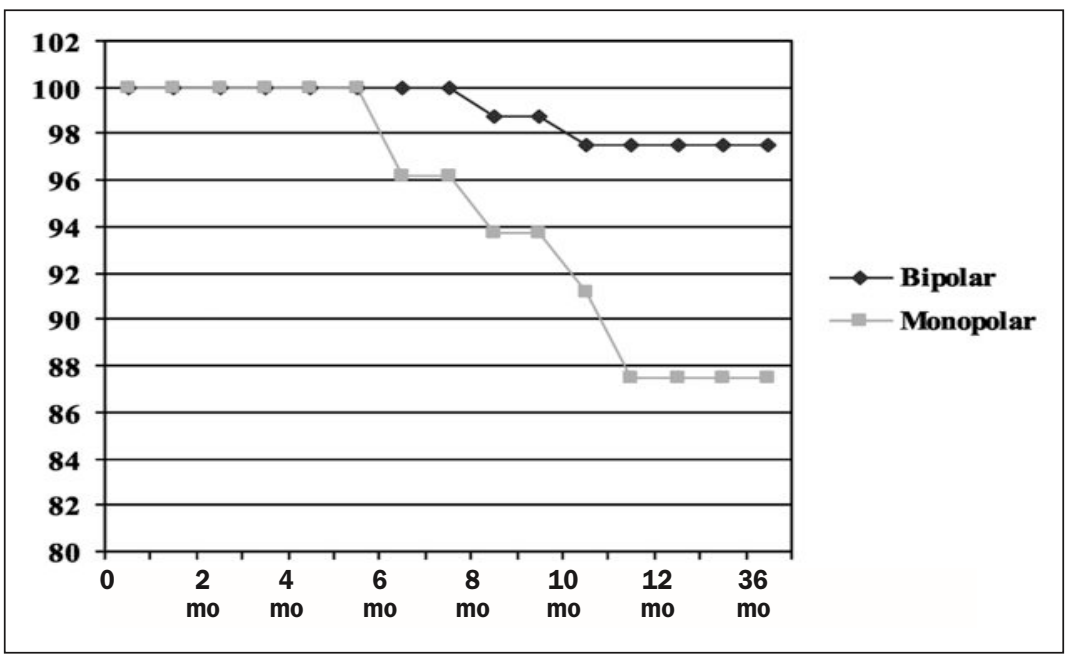

had incontinence, whereas in total 12 patients $(7.79 \%)$ $10(6.49 \%)$ and $2(1.29 \%)$ in the monopolar and in the bipolar group respectively, required to be treated endoscopicallty for bladder neck contracture after 6 to 11 months postoperatively. After 24 and 36 months no more patients were submitted to retreatment. According to Kaplan-Meier plot, the 3-year overall surgical re-treatment-free rate was $92.5 \%$ (Figure 2).

\section{Discussion}

Benign prostatic hyperplasia (BPH) is a chronic agerelated condition, affecting approximately $50 \%$ of men older than 50 years, $75 \%$ of men older than 70 years and $90 \%$ of men older than 80 years (7). For many years open prostatectomy had been the primary treatment option in patients with benign prostatic hyperplasia until it was gradually replaced by transurethral resection of the prostate (TURP). Although TURP is still regarded as the gold standard in patient with $\mathrm{BPH}$, it is associated with significant morbidity rates. Neal et al. (8) reported a $10 \%$ morbidity rate in patients submitted to TURP to remove obstruction. In our experience, the tissue ablation with the bipolar device was found to have similar clinical outcome compared to the standard procedure using a monopolar device, but with a significantly reduced bleeding rate.

Furthermore coagulation areas are found to be smaller when the bipolar resectoscope is used, due to the locally limited energy field between the electrodes of the resectoscope in which high power levels are achieved. This high energy field effectively coagulates bleeding vessels at the surface of the resected tissue. Deeper tissue layers are less affected indicating that no energy is wasted to them and distant negative effects, such as deep tissue heating, nervous or muscle stimulation and interfering with cardiac pace-maker, are reduced. The rate of tissue ablation of bipolar resection was comparable to that achieved by a standard resection loop.

In the current study we report the durable effect of bipolar TURP. In our study the improvement in micturition and symptom scores were immediate and IPSS, peak urinary flow rates and post-void residual urine volume returned to normal within 1 month postoperatively in each group. In the first postoperative month IPSS, Qol and $\mathrm{Q}_{\max }$ were better in the monopolar group than in the bipolar, but in all subsequent postoperative follow-up examinations were comparable in the 2 groups. At 3 years postoperatively, in the bipolar group, $\mathrm{Q}_{\max }$ increased significantly and post-void residual urine volume and PSA declined.

At 3 year follow up, improvement was significantly maintained for IPSS, IIEF-5 and Qol in both monopolar and bipolar group in comparison to baseline parameters (Figure 3-5), but without statistically significant difference between 2 groups.

Many advantages of bipolar TURP compared with monopolar are related to the haemostatic properties of the first device. Intraoperative blood loss and postoperative bleeding were significantly decreased in bipolar group. No patients treated with bipolar TURP required blood transfusion in contrast to three in the monopolar group. Few investigations have been done on the histopathological changes and the depth of coagulation after bipolar and monopolar TURP. Huang et al. (9) compared the coagulation depth and specimen changes of 
Figure 3.

3 year IPSS improvement in monopolar and bipolar group. Compared to baseline there was an highly significant improvement at all intervals in each group ( $p<0.0001)$, while there was no significant difference between the 2 groups in IPSS score at any time.

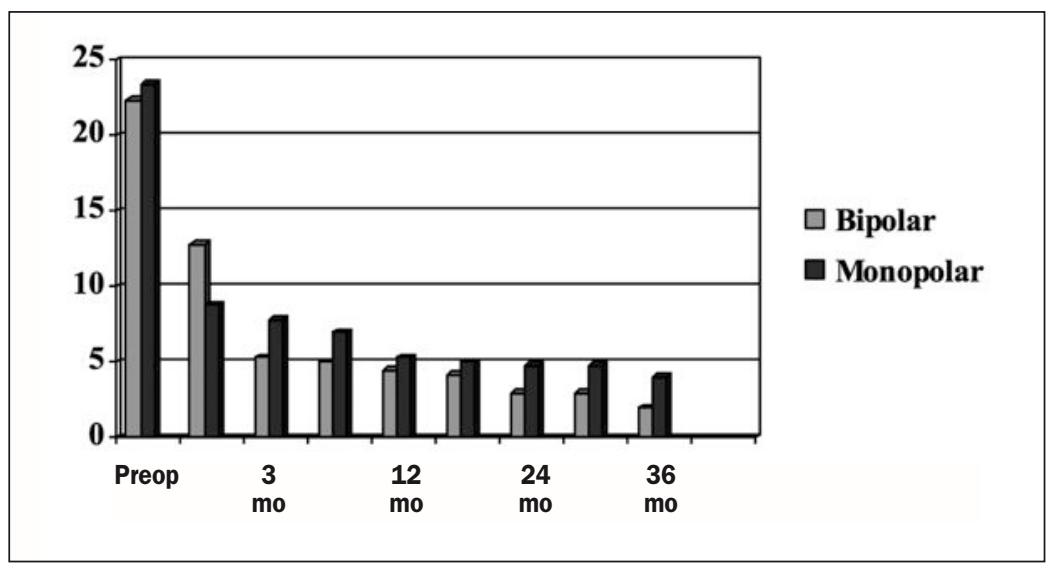

Figure 4.

A 3 years Qol improvement in Monopolar and Bipolar group. Compared to baseline there was highly significant improvement in each parameter at all intervals in each group ( $p<0,0001)$, while there was no significant difference between the 2 groups in Qol rates at any time.

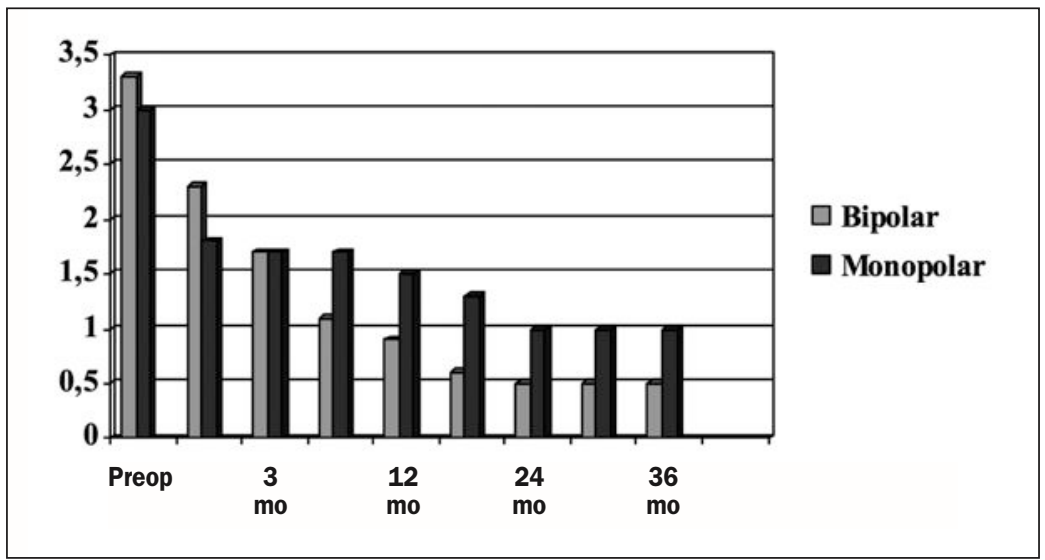

Figure 5.

A 3 years IIEF-5 improvement in monopolar and bipolar group.

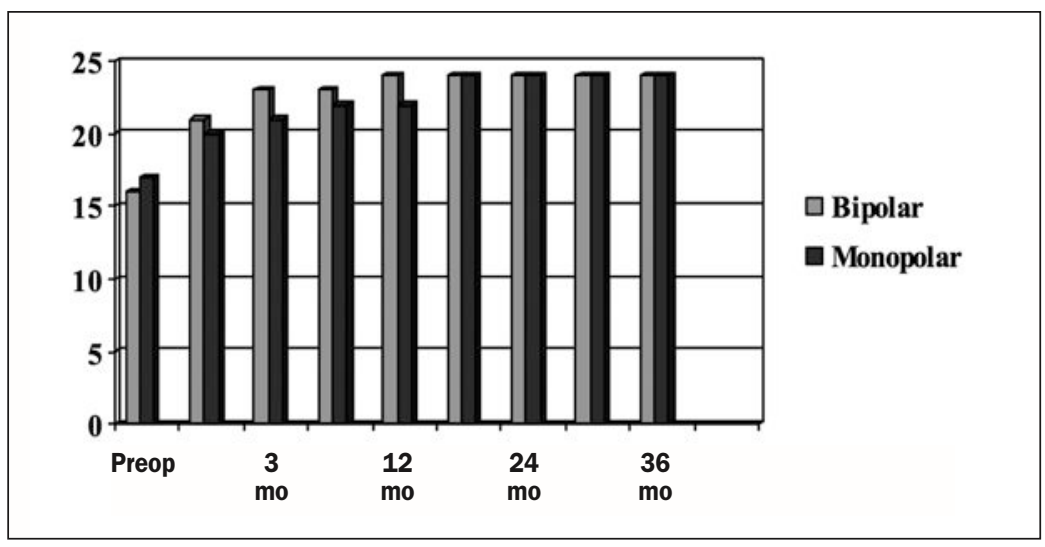

the prostate after bipolar and monopolar transurethral resection of the prostate in a canine model. The results of this study showed that the pathologic changes in the prostate after bipolar and monopolar TURP are similar, but coagulation areas of bipolar TURP are deeper and become thinner early after the operation than those the monopolar TURP. Botto et al. (10) found no significant intraoperative bleeding in 42 treated patients and Eaton et al. (11) found that no patient required blood transfusion and no patients showed electrolyte disturbances intraoperatively.

As a consequence of decreased bleeding in bipolar group, postoperative bladder irrigation, catheter time and hospital stay were significantly shorter than after monopolar TURP. Borboroglu et al. (12) recently reported a $0.4 \%$ transfusion rate, an average hospital stay of 1.1 days and an average catheter time of 1.4 days after TURP. Passavanti et al. (13) observed in 20 patients submitted to Plasmakinetic resection the possibility to quickly stop continuous irrigation and to early remove the catheter.

Initially, in our experience with bipolar resection operative time was longer compared to standard TURP, which could be due to the learning curve period.

In both groups Post- Voidal Residual Urine (PVR) significantly decreased after treatment. PVR has traditionally been considered as an important parameter in the evaluation of patients with clinically evident BPH. Several guidelines on the management of BPH consider PVR as a recommended (14) or optional (15) test in the clinical evaluation of patient with BPH.

Another advantage of bipolar versus monopolar electrocautery lays in the use of $0.9 \%$ sodium chloride solution for irrigation. Therefore the risk of TUR syndrome, resulting from the absorption of large amounts of irrigation fluid during prolonged procedures, is theoretically reduced (16).

Dunsmuir et al. (17) report about a randomized prospective study comparing bipolar electro vaporization of the prostate with the Gyrus device to the conventional TURP. After one year follow-up symptom scores, Qol, flow rates and post-voidal residual volumes were similar. They reported that re-catheterization was higher (30\% vs 5\%) in the bipolar vaporization group although the rate of postoperative clot evacuation was higher in the conventional TURP group. In the bipolar group the 3-year surgical 
re-treatment-free rate was lower than in the monopolar (2 vs 10 patients).

Varkarakis e al (18) reported on long-term morbidity in 577 patients with a minimum follow-up of 10 years. The total re-intervention rate was $6 \%$, including $2.4 \%$ who required reoperation for bladder neck contracture, $1.9 \%$ for recurrent BPH obstruction, and 1.7\% for urethral stricture. The annual rate of reoperation after minimal TURP is $2.5 \%$ and the reoperation rate at 8 year follow-up is 23\% after minimal resection and 7\% after TURP (11).

\section{Conclusion}

The main advantages of bipolar TURP is the use of saline as irrigation fluid, that eliminates the risk of Trans Urethral Resection Syndrome (TUR Syndrome) and the return current, reducing the risk of burns and the stimulation of nerves. In addition, the improved coupling of cut and coagulation may lead to less blood loss.

Bipolar TURP has a comparable outcome to standard monopolar TURP at short and medium term in term of subjective and objective outcome measures. Its impact on bladder outlet function is also similar to that of monopolar TURP. Improvement in IPSS, Qol index, IIEF-5, $Q_{\max }$ and post-void residual urine volume were comparable in both group denoting similar efficacy of the devices.

Furthermore, intraoperative blood loss, postoperative bleeding, time to catheterization, hospital-stay and the 3-year surgical re-treatment-free rate were significantly decreased with the use of the bipolar tool.

\section{References}

1. Keoghane SR, Lawrence KC, Gray AM, et al. A double-blind randomized controlled trial and economic evaluation of transurethral resection vs contact laser vaporization for benign prostatic enlargement: a 3-year follow-up. BJU Int. 2000; 85:74-8.

2. Down JB, Cochett ATK, Peters PC et al. Transurethral prostatectomy: practice aspects of the dominant operations in American Urology. J Urol. 1989; 141:248

3. Mebust WK, Holtgrewe HL, Cochett ATK, et al. Transurethral prostatectomy: immediate and post-operative complications. A cooperative study of 13 Institutions evaluating 3,885 patients. J Urol. 1989; 141:243.

4. Hahn RG, Nilsson A, Farahmand BY, et al. Blood haemoglobin and the long term incidence of acute myocardal infarction after transurethral resection of the prostate. Eur Urol. 1997; 31:199.

5. Uchida T, Ohori M, Soh S, et al. Factors influencing morbidity in patients undergoing transurethral resection of the prostate. Urology. 1999; 53:98.

6. Kellow NH. Pacemaker failure during transurethral resection of the prostate. Anaestesia. 1993; 48:136-8.

7. Cabelin MA, Te AE, Kaplan SA. Benign prostatic hyperplasia: challenges for the new millennium. Curr Opin Urol. 2000; 10:301.

8. Neal DE. The national Prostatectomy Audit. Br J Urol. 1997; 79:69.

9. Huang X, Wang X-H, Qu L-J, et al. Bipolar versus monopolar transurethral resection of the prostate: Pathologic Study in Canines. Urology. 2007; 70:180-184.
10. Botto H, Lebret T, Barre P, et al. Electrovaporization of the prostate with the Gyrus device. J Endourol. 2001; 15:313-6.

11. Eaton AC, Francis RN. The provision of transurethral prostatectomy on a day-case basis using bipolar plasma kinetic technology. BJU. 2002; 89:453-7.

12. Borboroglu PG, Krane CJ, Ward JF, et al. Immediate and postoperative complications of transurethral prostatectomy in the 1990's. J Urol. 1999; 162:1307.

13. Passavanti G, Pizzuti V, Bragaglia A, et al. The use of bipolar Plasmakinetic resectoscope in endoscopic resection of the prostate: our experience. Urologia. 2007; 74:160-163.

14. Abrams P, Griffiths D, Hofner K, et al. The urodynamic assessment of lower urinary tract symptoms. In Chatelain C, Denis L, Foo KT, et al. (eds.). Benign Prostatic Hyperplasia. Proceedings of the 5th International Consultation on Benign Prostatic Hyperplasia. Paris, June 25-28, 2000. Paris: Health Pubblication, Ltd, 2001; 227-281.

15. AUA, Practice Giudelines Committee: AUA guideline on management of benign prostatic hyperplasia (2003). Chapter 1: diagnosis and treatment recommendations. J Urol. 2003; 170:530.

16. Aagaard J, Jonler M, Fuglsig S, et al. Total transurethral resection versus minimal transurethral resection of the prostate-a 10years follow-up study of urinary symptoms, uroflowmetry and residual volume. Br J Urol. 2006; 50:563-8.

17. Dunsmuir WD, McFarlane JP, Tan A, et al. Gyrus bipolar electrovaporization vs transurethral resection of the prostate: a randomised prospective single-bind trial with a 1 year. follow up. Prostate Cancer Prostatic Dis. 2003; 6:182-6

18. Varkarakis J, Bartsch G, Horninger W. Long term morbidity and mortality of transurethral prostatectomy: a 10-year follow-up. Prostate. 2004; 58:248-51.

\author{
Correspondence \\ Roberto Giulianelli, MD \\ roberto.giulianelli@virgilio.it \\ Luca Albanesi, MD \\ lucalbanesi@hotmail.com \\ Stefano Brunori, MD \\ Barbara Cristina Gentile, MD \\ Giorgio Vincenti, MD \\ Stefano Nardoni, MD \\ Francesco Pisanti, MD \\ Teuta Shestani, MD \\ Luca Mavilla, MD \\ Francesco Attisani, MD \\ Gabriella Mirabile, MD \\ Manlio Schettini, MD \\ Division of Urology - Villa Tiberia Clinic, Rome, Italy
}

